\title{
Incidence and familial risks in pituitary adenoma and associated tumors
}

\author{
Kari Hemminki ${ }^{1,2}$, Asta Försti ${ }^{1,2}$ and Jianguang $\mathrm{Ji}^{2}$ \\ ${ }^{1}$ Division of Molecular Genetic Epidemiology, German Cancer Research Center (DKFZ), Im Neuenheimer Feld 580, 69120 \\ Heidelberg, Germany \\ ${ }^{2}$ Karolinska Institute, Center for Family and Community Medicine, 14183 Huddinge, Sweden \\ (Requests for offprints should be addressed to K Hemminki; Email: k.hemminki@dkfz.de)
}

\begin{abstract}
Reliable data on familial risks are important for clinical counseling and cancer genetics. We wanted to study incidence trends and familial risks for pituitary adenomas and associated tumors through parental and sibling probands, using the nation-wide Swedish Family-Cancer Database on 10.5 million individuals, containing families with parents and offspring. Cancer data were retrieved from the Swedish Cancer Registry from years 1958 to 2002, including 3239 pituitary tumor patients. Familial risk for offspring was defined through standardized incidence ratio (SIR), adjusted for many variables. The incidence of pituitary adenoma has increased moderately from 1958 to the 1990s and declined thereafter. There were only three offspring-parent pairs with a concordant pituitary tumor, the SIR was not significant. Parental skin cancer (SIR 1.60) and leukemia (1.90, chronic lymphatic leukemia 2.59) were associated with offspring pituitary adenoma diagnosed at any age up to 70 years. There was a strong association of pituitary adenomas with nervous system hemangiopericytomas, SIR 182. The only significant association among siblings was between pituitary tumors and breast cancer (1.46). The risk of pituitary adenoma was marginally increased in individuals whose siblings were diagnosed with colorectal cancer. The results suggest an association of pituitary adenomas with nervous system hemangiopericytomas and breast and colorectal cancers, in addition to some other tumor types. Whether these associations can be explained by the recently identified pituitary adenoma predisposing gene, AIP, remains to be established.
\end{abstract}

Endocrine-Related Cancer (2007) 14 103-109

\section{Introduction}

Pituitary adenomas are indolent tumors, which account for $10-15 \%$ of all diagnosed intracranial neoplasms (Asa \& Ezzat 2002, DeLellis et al. 2004). Small adenomas may occur in up to $15 \%$ of pituitary glands examined at autopsy and over $20 \%$ in radiological examinations (Ezzat et al. 2004). It is believed that with the use of modern imaging techniques the diagnosed cases of pituitary adenoma are increasing (Asa \& Ezzat 2002). Being benign tumors, most cancer registration systems do not record pituitary adenomas, whereby the data on the related incidence trends and etiology are limited. Pituitary adenomas can be typed based on their hormone-secreting properties into lactotropic (prolactin secreting, 35\%), gonadotropic (follicle-stimulating hormone and luteinizing hormone, 35\%), somatotropic (growth hormone, GH,
$10-15 \%)$ and other tumor types, including tumors with mixed secreting patterns and non-secreting adenomas (Asa \& Ezzat 2002, DeLellis et al. 2004). According to World Health Organization Classification of tumors in endocrine organs, some $25-30 \%$ of the surgically removed pituitary adenomas secrete $\mathrm{GH}$, but in clinical series the incidence is lower due to the inclusion of medically treated tumors (DeLellis et al. 2004). GH overproduction may lead to excessive growth, diagnosed as acromegaly or gigantism.

Pituitary adenomas are manifested in two syndromes, multiple endocrine neoplasia 1 (MEN1) and Carney complex (DeLellis et al. 2004). MEN1 is characterized by high penetrance of tumors in endocrine glands and by biochemical evidence of hyperparathyroidism in a large majority of the affected individuals. Carney complex is very rare, featuring endocrine, cutaneous, and neural tumors 
(DeLellis et al. 2004). Recently, Daly et al. described a multinational series of 64 families with two or more affected individuals with pituitary adenoma, not belonging to the known syndromes (Daly et al. 2006b). Prolactinomas and GH-secreting tumors made up $74 \%$ of the cases. In half of the families, the tumors of affected individuals secreted the same hormone, while in the remaining families the tumors showed a different secretion pattern. In another recent study, Vierimaa et al. identified germline mutations in the aryl hydrocarbon receptor interacting protein $(A I P)$ gene in patients diagnosed with pituitary adenoma (Vierimaa et al. 2006). The tumors were oversecreting $\mathrm{GH}$ or prolactin, and the phenotype in the families was acromegaly or gigantism. Many patients lacked a strong family history, suggesting that AIP is a low-penetrance tumor susceptibility gene. Because of the low penetrance, inherited predisposition to AIP may be difficult to detect in families in a clinical setting. None of these studies assessed the presence of associated tumors in families presenting pituitary adenomas.

The Swedish Cancer Registry has recorded even benign intracranial tumors throughout its existence, since 1958. These data give us a possibility to follow national incidence trends for pituitary adenoma. Additionally, based on the nation-wide Swedish Family-Cancer Database, we have the possibility to assess familial risks for pituitary adenoma and examine whether these tumors would be associated with other tumors in families. Based on the assumption that colorectal cancer is increased in acromegaly patients (Webb et al. 2002, Bogazzi et al. 2006, Jenkins et al. 2006), we examine specifically the familial associations between pituitary adenomas and colorectal cancer.

\section{Materials and methods}

The Swedish Cancer Registry was established in 1958. According to the instructions by the National Board of Health and Welfare, all physicians in hospitals and other establishments for medical treatment in Sweden must report all cases of cancer and benign intracranial tumors (clinical report) to the Cancer Registry. Furthermore, pathologists and cytologists report every cancer diagnosis on surgically removed tissues, biopsies, cytological specimens, bone marrow aspirates, and autopsies (pathology report) to the Registry. Thus the majority of cases are notified twice, in separate reports; cancer registration is currently considered to be close to $100 \%$ for invasive tumors (Center for Epidemiology 2004). The initial notifications are received by six regional oncology centers, which control the quality of the reports. Some 100 pituitary adenomas are reported annually, compared with a total of some 50000 cancers; thus, tumor-type specific features, such as hormonal correlates of pituitary adenomas have not been separately recorded. Incidences of pituitary adenomas, standardized according to the Swedish standard population as of December 31, 2000, were available in the Swedish Cancer Registry from years 1958 to 2003.

Statistics Sweden maintains a 'Multigeneration Register' where children, offspring, born in Sweden in 1932 and later (maximally 70 years old) are registered with their biological parents and are organized as families. False paternity cannot be excluded, but, if present, results would be biased towards null. The 'Multigeneration Register' was linked using the individually unique national registration number to the Cancer Registry to establish the Swedish FamilyCancer Database (Hemminki et al. 2001b). All data in the Family-Cancer Database were accrued by register linkages and thus reporting bias, common in interview studies, cannot be present. The Database was last updated in 2004, and included cancer cases from 1958 to 2002. A four-digit diagnosis code according to the seventh revision of the International Classification of Diseases (ICD-7) has been used. Basal cell carcinoma of the skin is not registered in the Cancer Registry. Only the first primary pituitary adenoma was considered in the present study. Information on family history was collected on all first-degree relatives (parents and siblings). Standardized incidence ratios (SIRs) were used to measure the cancer risks for offspring according to the occurrence of cancers in their families. The follow-up was started for each offspring at birth, immigration, or on 1 January, 1961, whichever was the latest time. Follow-up was terminated at the diagnosis of first cancer, death, emigration, or the closing date of the study on 31 December, 2002. Parents' ages were not limited, but offspring were 0-70 years of age. SIRs were calculated as the ratio of observed (O) to expected (E) number of cases. The expected numbers were calculated from 5-year-age-, gender-, tumor type-, period-, and socioeconomic status- (six groups) specific standard incidence rates for all offspring lacking a family history (Esteve et al. 1994). Confidence intervals (95\% CIs) were calculated assuming a Poisson distribution, and they were rounded to the nearest two decimals (Esteve et al. 1994). Risks for siblings were calculated using the cohort method in this study, which considers each sibling separately and is practically independent of the number of siblings (Hemminki et al. 2001a). 


\section{Results}

The incidence trends of pituitary adenomas for men and women are shown in Fig. 1, based on the data from the Swedish Cancer Registry. The male incidence increased from $0.9 / 100000$ in years $1958-1959$ to a maximum of $1.9 / 100000$ in years $1995-1999$, and it has decreased to $1.3 / 100000$ in the last period of 2000 2003. The female incidence was initially very similar to the male rate but since then it has been lower. The age-incidence curves for pituitary adenomas are shown in Fig. 2, based on a total of 3239 pituitary tumor patients identified from the Family-Cancer Database. The female incidence was higher than the male one for ages below 30 years, but at the higher age groups the incidence rates were reversed. The male incidence reached a sharp maximum around age 70-74 years compared with a flatter female curve.

Familial risks for offspring pituitary adenomas are shown in Table 1, when their parents were diagnosed with any cancers. There were only three offspringparent pairs with a concordant pituitary tumor (SIR 1.77, 95\%CIs 0.33-5.25). Parental skin cancer (SIR 1.60) and leukemia (1.90) associated with offspring pituitary adenoma diagnosed at any age up to 70 years. Skin cancers were mainly squamous cell carcinomas. The association of offspring pituitary tumors and parental colorectal cancer was of borderline significance $(1.20,0.97-1.48)$. Early onset $(<30$ years) pituitary tumors in offspring associated with parental endocrine gland tumors and leukemia; pituitary tumors, diagnosed at ages 30-45 years were in excess in offspring whose mothers were diagnosed with breast cancer. In order to examine the possible role of MEN1 or Carney complex, in the noted associations when all families with endocrine gland tumors, other than pituitary adenomas, were excluded; all the noted significant associations were essentially unchanged.

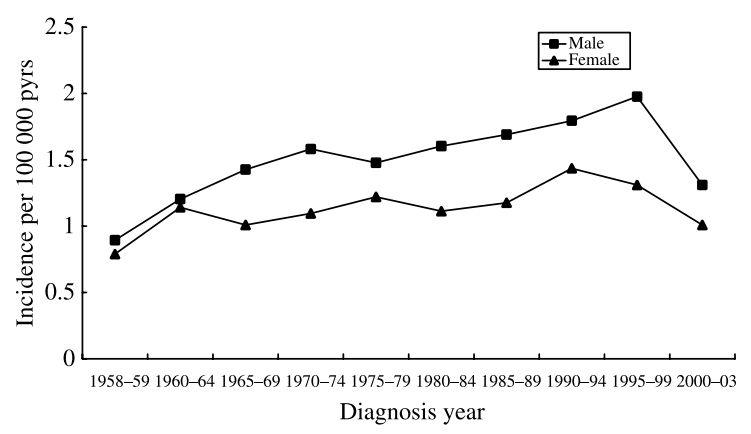

Figure 1 Incidence trends of pituitary adenomas for men and women, based on the data from the Swedish Cancer Registry from year 1958 to 2003 .

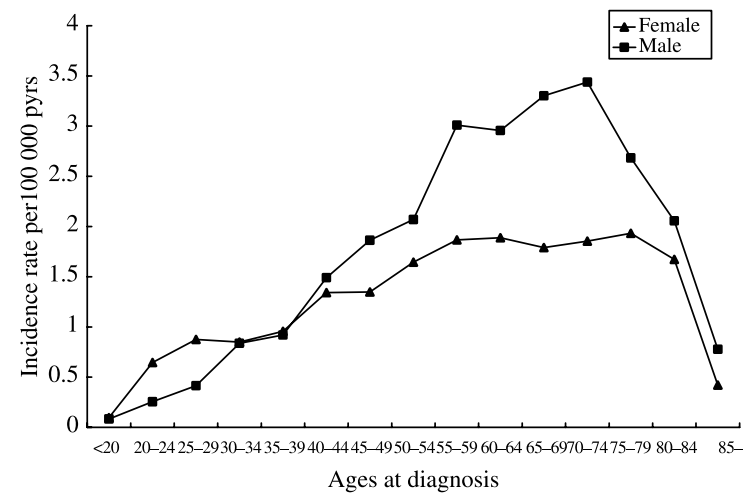

Figure 2 Age-incidence curves for pituitary adenomas, based on a total of 3239 pituitary tumor patients identified from the Family-Cancer Database.

A separate analysis was carried out for the risk of pituitary adenoma when a sibling presented with any cancer (Table 2). No sibling pairs with concordant pituitary tumors were found. The only significant association was between pituitary tumors and breast cancer (1.46), particularly with early onset (below 41 years) pituitary tumors (1.73). Late onset pituitary tumors were also associated with sibling's kidney cancer (four adenocarcinomas and two transitional cell carcinomas) and Hodgkin's disease. The risk of pituitary adenoma was marginally increased in individuals whose siblings were diagnosed with colorectal cancer (1.65, 0.92-2.73).

The risk for pituitary adenoma is shown in Table 3 according to a specific type of leukemia in parents. Although pituitary adenomas showed SIRs above unity when parents were diagnosed with many leukemia subtypes, the only significant association was with parental chronic lymphatic leukemia (2.59), particularly for adenomas diagnosed after age 40 years (2.96); however, this type of leukemia also showed the most cases.

We analyzed in more detail the associations of pituitary adenomas with other nervous system tumors. No association was found with any of the main tumor types, astrocytoma, menigioma, ependymoma, and neurinoma; however, hemangiopericytoma associated with pituitary tumors, and the SIR was excessive, 182 $(N=2$, 95\%CIs 17-670, diagnostic ages 52 and 54 years). Remarkably, only 15 nervous system hemangiopericytomas were found in the whole database, and 2 of them associated with pituitary tumors in families.

\section{Discussion}

Thanks to the registration of pituitary adenomas in the Swedish Cancer Registry, we were able to follow the 
Table 1 Familial risk for pituitary tumors in offspring diagnosed at different ages when parents were affected with cancers

\begin{tabular}{|c|c|c|c|c|c|c|c|c|c|c|c|c|c|c|c|c|}
\hline \multirow{3}{*}{$\begin{array}{l}\text { Familial site } \\
\begin{array}{l}\text { Upper aerodigestive } \\
\text { tract }\end{array}\end{array}$} & \multicolumn{4}{|c|}{ All age } & \multicolumn{4}{|c|}{$<\mathbf{3 0}$ Years } & \multicolumn{4}{|c|}{ 30-45 Years } & \multicolumn{4}{|c|}{$>45$ Years } \\
\hline & \multirow{2}{*}{$\frac{0}{12}$} & \multirow{2}{*}{$\frac{\operatorname{SIR}}{0.81}$} & \multicolumn{2}{|c|}{$95 \% \mathrm{Cl}$} & \multirow{2}{*}{$\frac{O}{5}$} & \multirow{2}{*}{$\frac{\operatorname{SIR}}{1.89}$} & \multicolumn{2}{|c|}{$95 \% \mathrm{Cl}$} & \multirow{2}{*}{$\frac{O}{5}$} & \multirow{2}{*}{$\frac{\text { SIR }}{0.85}$} & \multicolumn{2}{|c|}{$95 \% \mathrm{Cl}$} & \multirow{2}{*}{$\frac{0}{2}$} & \multirow{2}{*}{$\frac{\text { SIR }}{0.32}$} & \multicolumn{2}{|c|}{$95 \% \mathrm{Cl}$} \\
\hline & & & 0.42 & 1.42 & & & 0.60 & 4.44 & & & 0.27 & 1.99 & & & 0.03 & 1.17 \\
\hline Stomach & 26 & 0.82 & 0.54 & 1.21 & 3 & 0.67 & 0.13 & 2.00 & 9 & 0.77 & 0.35 & 1.46 & 14 & 0.91 & 0.49 & 1.53 \\
\hline Small intestine & 5 & 1.77 & 0.56 & 4.17 & 0 & & & & 2 & 1.75 & 0.17 & 6.45 & 3 & 2.57 & 0.48 & 7.60 \\
\hline Colon & 55 & 1.14 & 0.86 & 1.49 & 8 & 1.01 & 0.43 & 2.00 & 24 & 1.26 & 0.80 & 1.87 & 23 & 1.09 & 0.69 & 1.63 \\
\hline Rectum & 37 & 1.33 & 0.94 & 1.84 & 9 & 1.92 & 0.87 & 3.66 & 13 & 1.18 & 0.63 & 2.03 & 15 & 1.24 & 0.69 & 2.05 \\
\hline Liver & 18 & 0.90 & 0.53 & 1.43 & 3 & 0.97 & 0.18 & 2.88 & 11 & 1.43 & 0.71 & 2.56 & 4 & 0.43 & 0.11 & 1.12 \\
\hline Pancreas & 21 & 1.06 & 0.66 & 1.62 & 5 & 1.60 & 0.50 & 3.76 & 8 & 1.05 & 0.45 & 2.07 & 8 & 0.89 & 0.38 & 1.75 \\
\hline Lung & 46 & 1.00 & 0.73 & 1.34 & 5 & 0.59 & 0.19 & 1.40 & 20 & 1.06 & 0.65 & 1.6 & 21 & 1.13 & 0.70 & 1.72 \\
\hline Breast & 78 & 1.12 & 0.88 & 1.40 & 13 & 0.89 & 0.47 & 1.52 & 41 & 1.44 & 1.03 & 1. & 24 & 0.90 & 0.58 & 1.34 \\
\hline Cervix & 13 & 0.97 & 0.51 & 1.66 & 2 & 0.76 & 0.07 & 2.78 & 6 & 1.10 & 0.40 & 2.4 & 5 & 0.94 & 0.30 & 2.20 \\
\hline Endometrium & 22 & 1.28 & 0.80 & 1.93 & 4 & 1.27 & 0.33 & 3.29 & 7 & 0.99 & 0.39 & 2.0 & 11 & 1.57 & 0.78 & 2.81 \\
\hline Ovary & 20 & 1.31 & 0.80 & 2.03 & 4 & 1.39 & 0.36 & 3.6 & 10 & 1. & 0.78 & 3. & 6 & 0.96 & 0.35 & 2.11 \\
\hline Prostate & 89 & 0.97 & 0.78 & 1.19 & 12 & 0.76 & 0.39 & 1.34 & 39 & 1.05 & 0.75 & 1.44 & 38 & 0.97 & 0.69 & 1.34 \\
\hline Kidney & 16 & 0.76 & 0.43 & 1.23 & 3 & 0.82 & 0.15 & 2.42 & 7 & 0.83 & 0.33 & 1.72 & 6 & 0.66 & 0.24 & 1.44 \\
\hline Urinary blad & 25 & 0.81 & 0.53 & 1.20 & 4 & 0.74 & 0.19 & 1.9 & 12 & 0.97 & 0.50 & 1.6 & 9 & 0.70 & 0.32 & 1.33 \\
\hline Melanoma & 20 & 1.32 & 0.80 & 2.04 & 7 & 1.85 & 0.73 & 3.82 & 8 & 1.25 & 0.53 & 2.47 & 5 & 1.00 & 0.32 & 2.36 \\
\hline Skin & 37 & 1.60 & 1.13 & 2.21 & 6 & 1.66 & 0.60 & 3.64 & 14 & 1.54 & 0.84 & 2.5 & 17 & 1.64 & 0.95 & 2.63 \\
\hline Nervous system & 17 & 0.96 & 0.56 & 1.55 & 2 & 0.53 & 0.05 & 1.95 & 10 & 1.39 & 0.66 & 2.5 & 5 & 0.75 & 0.24 & 1.76 \\
\hline Thyroid gland & 7 & 1.42 & 0.56 & 2.95 & 2 & 1.89 & 0.18 & 6.97 & 3 & 1.53 & 0.29 & 4.53 & 2 & 1.06 & 0.10 & 3.88 \\
\hline Endocrine glands & 16 & 1.53 & 0.87 & 2.49 & 7 & 3.20 & 1.27 & 6.64 & 3 & 0.69 & 0.13 & 2.06 & 6 & 1.51 & 0.54 & 3.31 \\
\hline Pituitary cancer & 3 & 1.77 & 0.33 & 5.25 & 2 & 5.00 & 0.47 & 18.37 & 1 & 1.43 & 0.00 & 8.22 & 0 & & & \\
\hline Connective tissue & 3 & 0.74 & 0.14 & 2.18 & 0 & & & & 2 & 1.23 & 0.12 & 4.51 & 1 & 0.60 & 0.00 & 3.46 \\
\hline $\begin{array}{l}\text { Non-Hodgkin's } \\
\text { lymphoma }\end{array}$ & 18 & 1.01 & 0.59 & 1.59 & 6 & 1.74 & 0.63 & 3.81 & 5 & 0.69 & 0.22 & 1.62 & 7 & 0.97 & 0.39 & 2.02 \\
\hline Hodgkin's disease & 4 & 1.35 & 0.35 & 3.49 & 0 & & & & 1 & 0.87 & 0.00 & 5.00 & 3 & 2.46 & 0.46 & 7.28 \\
\hline Myeloma & 15 & 1.51 & 0.84 & 2.49 & 4 & 2.45 & 0.64 & 6.34 & 4 & 1.03 & 0.27 & 2.66 & 7 & 1.58 & 0.62 & 3.27 \\
\hline Leukemia & 34 & 1.90 & 1.31 & 2.66 & 8 & 2.56 & 1.09 & 5.07 & 12 & 1.70 & 0.87 & 2.97 & 14 & 1.82 & 0.99 & 3.06 \\
\hline All & 506 & 1.03 & 0.94 & 1.12 & 99 & 1.07 & 0.87 & 1.31 & 212 & 1.07 & 0.93 & 1.22 & 195 & 0.97 & 0.84 & 1.12 \\
\hline
\end{tabular}

Bold type, $95 \% \mathrm{Cl}$ does not include 1.00 .

incidence trends of these tumors since the start of the registration 1958. The registration primarily covers clinically recognized tumors, which is a small proportion of all pituitary adenomas (Ezzat et al. 2004). An extensive discussion on the incidence and prevalence rates of pituitary adenomas was recently published (Daly et al. 2006a). The Swedish Cancer Registry actually also includes tumors found at autopsy, but pituitary adenomas appear to be almost completely overlooked because the autopsy material provides few new cases (Center for Epidemiology 2004). The reason may be that in a routine autopsy there are no resources to carry out detailed analyses in order to verify whether any suspected finding is really a tumor. In this vein, only one percent of prostate cancer is reported from autopsies, a negligible addition to some 8000 clinically recognized tumors (Center for Epidemiology 2004). There has been a moderate increase in the incidence, particularly of male adenomas, up to the 1990 s, but since then the incidence appears to have declined. The increase in incidence in the early period may be related to an increase in active reporting, and in the later period to improved diagnostic techniques (Asa \& Ezzat 2002). The apparent decline after year 2000 has a number of speculative explanations: notification activity may have declined for unknown reasons or, perhaps, because imaging techniques have replaced traditional histological examinations. Moreover, the introduction of effective tools for early diagnostics is initially increasing the incidence of the disease and later decreasing the incidence towards a steadystate level, as shown for mammographic screening (IARC 2002).

The overall incidence of recorded pituitary adenomas, $1 / 100000$ was quite similar to the rate in the Central Brain Tumor Registry of the United States (www.cbtrus.org). The age-incidence patterns showed a typical high risk at old age; the female excess at ages before 35 years has been ascribed to prolactinomas because of their earlier presentation in women (Ciccarelli et al. 2005). One may argue that if this 
Table 2 Familial risk for pituitary tumors in offspring diagnosed at different ages when siblings were affected with cancers

\begin{tabular}{|c|c|c|c|c|c|c|c|c|c|c|c|c|}
\hline \multirow{3}{*}{$\begin{array}{l}\text { Familial site } \\
\text { Upper aerodigestive tract }\end{array}$} & \multicolumn{4}{|c|}{ All age } & \multicolumn{4}{|c|}{$\leq 40$ Years } & \multicolumn{4}{|c|}{$>40$ Years } \\
\hline & \multirow{2}{*}{$\frac{O}{4}$} & \multirow{2}{*}{$\frac{\text { SIR }}{1.45}$} & \multicolumn{2}{|c|}{$95 \% \mathrm{Cl}$} & \multirow{2}{*}{0} & \multirow{2}{*}{$\begin{array}{l}\text { SIR } \\
2.91\end{array}$} & \multicolumn{2}{|c|}{$95 \% \mathrm{Cl}$} & \multirow{2}{*}{$\frac{0}{1}$} & \multirow{2}{*}{$\frac{\text { SIR }}{0.58}$} & \multicolumn{2}{|c|}{$95 \% \mathrm{Cl}$} \\
\hline & & & 0.38 & 3.74 & & & 0.55 & 8.62 & & & 0.00 & 3.30 \\
\hline Stomach & 5 & 2.42 & 0.76 & 5.69 & 2 & 2.72 & 0.26 & 10.00 & 3 & 2.25 & 0.42 & 6.67 \\
\hline Small intestine & 1 & 1.82 & 0.00 & 10.44 & 1 & 4.89 & 0.00 & 28.03 & 0 & & & \\
\hline Colon & 9 & 1.53 & 0.69 & 2.92 & 4 & 1.86 & 0.48 & 4.80 & 5 & 1.34 & 0.42 & 3.16 \\
\hline Rectum & 6 & 1.62 & 0.58 & 3.56 & 2 & 1.52 & 0.14 & 5.58 & 4 & 1.68 & 0.44 & 4.35 \\
\hline Liver & 1 & 0.58 & 0.00 & 3.35 & 1 & 1.60 & 0.00 & 9.15 & 0 & & & \\
\hline Pancreas & 1 & 0.56 & 0.00 & 3.19 & 1 & 1.57 & 0.00 & 8.98 & 0 & & & \\
\hline Lung & 11 & 1.62 & 0.80 & 2.90 & 6 & 2.53 & 0.91 & 5.55 & 5 & 1.13 & 0.36 & 2.65 \\
\hline Breast & 38 & 1.46 & 1.03 & 2.01 & 17 & 1.73 & 1.00 & 2.77 & 21 & 1.30 & 0.80 & 1.99 \\
\hline Cervix & 4 & 0.94 & 0.25 & 2.44 & 2 & 1.08 & 0.10 & 3.96 & 2 & 0.84 & 0.08 & 3.09 \\
\hline Endometrium & 2 & 0.52 & 0.05 & 1.92 & 0 & & & & 2 & 0.79 & 0.07 & 2.92 \\
\hline Ovary & 4 & 0.92 & 0.24 & 2.37 & 2 & 1.20 & 0.11 & 4.43 & 2 & 0.74 & 0.07 & 2.72 \\
\hline Prostate & 10 & 1.30 & 0.62 & 2.40 & 3 & 1.22 & 0.23 & 3.62 & 7 & 1.33 & 0.53 & 2.76 \\
\hline Kidney & 7 & 2.20 & 0.87 & 4.56 & 1 & 0.85 & 0.00 & 4.87 & 6 & 3.00 & 1.08 & 6.56 \\
\hline Urinary bladder & 7 & 1.62 & 0.64 & 3.36 & 4 & 2.63 & 0.68 & 6.81 & 3 & 1.07 & 0.20 & 3.18 \\
\hline Melanoma & 8 & 0.95 & 0.40 & 1.87 & 3 & 0.83 & 0.16 & 2.47 & 5 & 1.03 & 0.32 & 2.42 \\
\hline Skin & 1 & 0.40 & 0.00 & 2.32 & 0 & & & & 1 & 0.64 & 0.00 & 3.68 \\
\hline Nervous system & 6 & 0.81 & 0.29 & 1.76 & 3 & 0.90 & 0.17 & 2.68 & 3 & 0.73 & 0.14 & 2.15 \\
\hline Thyroid gland & 0 & & & & 0 & & & & 0 & & & \\
\hline Endocrine glands & 4 & 1.07 & 0.28 & 2.76 & 0 & & & & 4 & 1.79 & 0.47 & 4.63 \\
\hline Connective tissue & 2 & 1.64 & 0.16 & 6.05 & 1 & 1.88 & 0.00 & 10.79 & 1 & 1.46 & 0.00 & 8.37 \\
\hline Non-Hodgkin's lymphoma & 3 & 0.63 & 0.12 & 1.87 & 1 & 0.54 & 0.00 & 3.09 & 2 & 0.69 & 0.07 & 2.54 \\
\hline Hodgkin's disease & 4 & 2.72 & 0.71 & 7.04 & 0 & & & & 4 & 5.40 & 1.40 & 13.96 \\
\hline Myeloma & 1 & 0.83 & 0.00 & 4.77 & 0 & & & & 1 & 1.28 & 0.00 & 7.31 \\
\hline Leukemia & 2 & 0.55 & 0.05 & 2.02 & 1 & 0.61 & 0.00 & 3.47 & 1 & 0.50 & 0.00 & 2.89 \\
\hline All & 75 & 1.14 & 0.90 & 1.43 & 30 & 1.15 & 0.77 & 1.64 & 45 & 1.14 & 0.83 & 1.52 \\
\hline
\end{tabular}

Bold type, $95 \% \mathrm{Cl}$ does not include 1.00 .

were correct, the female excess should be seen throughout the reproductive period. The counterargument is that, the number of cases being constant, are shifted into one age group leaves a deficit in another group. Pituitary tumors were found to be in excess in female, and to a lesser extent in male same-sex twins; this was speculated to be related to the postnatal growth period, during which twins catch up the weight of singletons but the hypothesis may not be correct because the effect was not seen in different sex twins (Hemminki \& Chen 2005).

Multiple comparisons are a major source of spurious results in the present kinds of studies. A formal approach to deal with the problem is to adjust the CIs to the number of comparisons; however, because there is no agreement on how the adjustment should be made, we emphasize the value of high SIRs and 95\%CIs extensively deviating from the borderline value of 1.00 .

Table 3 Familial risk for pituitary tumors when parents were affected with leukemia

\begin{tabular}{|c|c|c|c|c|c|c|c|c|c|c|c|c|}
\hline \multirow{3}{*}{$\begin{array}{l}\text { Leukemia subtypes } \\
\text { Acute lymphatic leukemia }\end{array}$} & \multicolumn{4}{|c|}{ All age } & \multicolumn{4}{|c|}{$\leq 40$ Years } & \multicolumn{4}{|c|}{$>40$ Years } \\
\hline & \multirow{2}{*}{$\frac{0}{2}$} & \multirow{2}{*}{$\frac{\mathrm{SIR}}{2.90}$} & \multicolumn{2}{|c|}{$95 \% \mathrm{Cl}$} & \multirow{2}{*}{$\frac{0}{1}$} & \multirow{2}{*}{$\frac{\text { SIR }}{3.29}$} & \multicolumn{2}{|c|}{$95 \% \mathrm{Cl}$} & \multirow{2}{*}{$\frac{0}{1}$} & \multirow{2}{*}{$\frac{\operatorname{SIR}}{2.60}$} & \multicolumn{2}{|c|}{$95 \% \mathrm{Cl}$} \\
\hline & & & 0.27 & 10.68 & & & 0.00 & 18.87 & & & 0.00 & 14.89 \\
\hline Chronic lymphatic leukemia & 17 & 2.59 & 1.51 & 4.16 & 6 & 2.11 & 0.76 & 4.62 & 11 & 2.96 & 1.47 & 5.31 \\
\hline Acute myeloid leukemia & 6 & 1.64 & 0.59 & 3.58 & 4 & 2.38 & 0.62 & 6.16 & 2 & 1.01 & 0.09 & 3.70 \\
\hline Chronic myeloid leukemia & 2 & 1.07 & 0.10 & 3.92 & 1 & 1.22 & 0.00 & 7.00 & 1 & 0.95 & 0.00 & 5.42 \\
\hline Polycythaemia vera & 5 & 2.08 & 0.66 & 4.89 & 3 & 2.95 & 0.56 & 8.74 & 2 & 1.44 & 0.14 & 5.29 \\
\hline Myelofibrosis & 2 & 2.70 & 0.25 & 9.93 & 1 & 2.81 & 0.00 & 16.11 & 1 & 2.60 & 0.00 & 14.91 \\
\hline Other leukemia & 2 & 1.96 & 0.18 & 7.19 & 0 & & & & 2 & 3.29 & 0.31 & 12.09 \\
\hline All leukemia & 34 & 1.90 & 1.31 & 2.66 & 15 & 1.91 & 1.07 & 3.16 & 19 & 1.89 & 1.14 & 2.96 \\
\hline
\end{tabular}

Bold type, $95 \% \mathrm{Cl}$ does not include 1.00 . 
Other pointers are biological plausibility and agreement with previous hypotheses and results, all of which will be evoked in the discussion below.

Among a total of 3239 pituitary tumor patients, only 3 concordant parent-offspring pairs were identified and although the familial SIR was clearly above unity (1.77), it was not significant. However, the proportion of familial cases may not be substantially smaller than that in the European study by Daly et al. (2006b). The size of the covered population was not given in that study but two of the participating 22 clinics were able to provide a sporadic population of 2600 pituitary adenoma patients diagnosed after age 34 years. One can assume that the population covered by all the 22 clinics thus far exceeded the population covered by the Swedish Database. Furthermore, being clinically based, the European study could identify affected family members back in history (Daly et al. 2006b).

Colorectal cancer is the only cancer type considered to be increased in acromegaly patients (Jenkins et al. 2006). Since only some $25-30 \%$ of the surgically removed pituitary adenomas secrete GH (DeLellis et al. 2004) and since our Database contains no details on the hormone-secreting properties of the tumors, we decided to test whether an indication of GH adenoma involvement could be found through a possible association of pituitary adenomas with colorectal cancer in families. Indeed, the risk of pituitary adenoma was marginally increased in individuals whose parents or siblings were diagnosed with colorectal cancer. Although we cannot definitely exclude contribution by other syndromes with a pituitary involvement, such as MEN1 and Carney complex (DeLellis et al. 2004), the results were identical when the analyses were repeated after the removal of all families presenting with any endocrine tumors other than pituitary adenomas. The Database contains no information on cancer syndromes but these can be deduced from pathognomonic presentation of tumors. We have reported elsewhere that, according to the Family-Cancer Database, the risk for a second pituitary tumor after an initial pituitary tumor is increased (Hemminki \& Jiang 2001); in the most recent followup, the risk was $15.0(8.2-25.2, N=14)$; pituitary tumors were also in excess in patients first diagnosed with colorectal cancer (SIR 2.2, 1.5-3.1, N=30; Hemminki et al. 2006). These data were considered to provide population-level support to the notion that GH-secreting pituitary adenomas constitute an inherited cancer predisposition with a low risk and perhaps many apparently sporadic cases (Daly et al. 2005a,b, Vierimaa et al. 2006).
The novel findings of the present study concerned the associated tumors, most notably hemangiopericytoma, with a familial association of 182 . Although only two nervous system hemangiopericytomas were diagnosed in families presenting with pituitary adenoma, there were no more than 15 cases of these tumors in the Family-Cancer Database, covering a population base of 10.5 million. Being extremely rare tumors, the literature on hemangiopericytomas is limited. The WHO Pathology and Genetics series refers to a case report on one family with three affected individuals (Kleihues \& Cavenee 2000). Interestingly, hemangiopericytomas, as many other tumors, are thought to be rich in insulin-like growth factor receptors, thus potentially mechanistically linking these tumors to the GH-pathway (Elias et al. 2002).

Among the tumors that associated with pituitary adenoma in families, breast cancer could also possibly be linked to GH overproduction, as suggested in some previous studies (Webb et al. 2002, Bogazzi et al. 2006, Jenkins et al. 2006). Moreover, there is a strong evidence associating prolactin overproduction with an increased risk of postmenopausal breast cancer and prolactin genotypes with familial breast cancer (Tworoger \& Hankinson 2006, Tworoger et al. 2006, Vaclavicek et al. 2006). The associations of pituitary adenoma with breast cancer were obtained among parents and offspring, and among siblings, strengthening the evidence. The other associated neoplasms, chronic lymphatic leukemia, kidney and skin cancers and Hodgkin's disease were detected either through parental or sibling probands, but not with both, and they need to be confirmed in other settings. Interestingly, all these associations tended to be stronger in older pituitary tumor patients.

This nationwide study on familial pituitary adenomas suggested an association with nervous system hemangiopericytomas and breast and colorectal cancers, in addition to some other tumor types. These associated tumors have not been reported as manifestations in MEN1 or Carney complex. Whether they are linked to the recently characterized AIP mutations remains to be established.

\section{Acknowledgements}

The Family-Cancer Database was created by linking registries maintained by Statistics Sweden and the Swedish Cancer Register, and supported by the Deutsche Krebshilfe, the Swedish Cancer Society, the Swedish Council for Working Life and Social Research and the EU, LSHC-LT-2004-503465. The authors declare that there is no conflict of interest that would prejudice the impartiality of this scientific work. 


\section{References}

Asa S \& Ezzat S 2002 The pathogenesis of pituitary tumours. Nature Reviews. Cancer 2 836-849.

Bogazzi F, Cosci C, Sardella C, Costa A, Manetti L, Gasperi M, Rossi G, Bartalena L \& Martino E 2006 Identification of acromegalic patients at risk of developing colonic adenomas. Journal of Clinical Endocrinology and Metabolism 91 1351-1356.

Center for Epidemiology 2004 Cancer Incidence in Sweden 2002, pp. www.sos.se. Stockholm: the National Board of Health and Welfare.

Ciccarelli A, Daly AF \& Beckers A 2005 The epidemiology of prolactinomas. Pituitary 8 3-6.

Daly AF, Petrossians P \& Beckers A $2005 a$ An overview of the epidemiology and genetics of acromegaly. Journal of Endocrinological Investigation 28 67-69.

Daly AF, Jaffrain-Rea ML \& Beckers A 2005b Clinical and genetic features of familial pituitary adenomas. Hormone and Metabolic Research 37 347-354.

Daly AF, Rixhon M, Adam C, Dempegioti A, Tichomirowa MA \& Beckers A $2006 a$ High prevalence of pituitary adenomas: a cross sectional study in the province of Liege, Belgium. Journal of Clinical Endocrinology and Metabolism 91 4769-4775.

Daly AF, Jaffrain-Rea ML, Ciccarelli A, Valdes-Socin H, Rohmer V, Tamburrano G, Borson-Chazot C, Estour B, Ciccarelli E, Brue T et al. 2006b Clinical characterization of familial isolated pituitary adenomas. Journal of Clinical Endocrinology and Metabolism 91 3316-3323.

DeLellis R, Lloyd R, Heitz P \& Eng C 2004 Pathology and genetics of tumours of endocrine origin. In World Health Organization Classification of Tumours, pp 320. Lyon: IARC Press, Lyon.

Elias WJ, Hussaina IM, Chadduck JB, Jane JA, Laws ER Jr \& Lopes MB 2002 Hemangiopericytoma in the setting of acromegaly. Endocrine Pathology 13 251-261.

Esteve J, Benhamou E \& Raymond L 1994 Statistical Methods in Cancer Research. Lyon: IARC Press.

Ezzat S, Asa SL, Couldwell WT, Barr CE, Dodge WE, Vance ML \& McCutcheon IE 2004 The prevalence of pituitary adenomas: a systematic review. Cancer 101 613-619.
Hemminki K \& Chen B 2005 Are twins at risk of cancer: results from a Swedish Family-Cancer Database. Twin Research and Human Genetics 8 509-514.

Hemminki K \& Jiang Y 2001 Second primary neoplasms after 19281 endocrine gland tumours: aetilogical links? European Journal of Cancer 37 1886-1894.

Hemminki K, Vaittinen P, Dong C \& Easton D 2001 $a$ Sibling risks in cancer: clues to recessive or X-linked genes? British Journal of Cancer 84 388-391.

Hemminki K, Li X, Plna K, Granström C \& Vaittinen P $2001 b$ The nation-wide Swedish Family-Cancer Database: updated structure and familial rates. Acta Oncologica 40 772-777.

Hemminki K, Försti A \& Ji J 2006 Pituitary adenoma predisposition. Journal of Clinical Endocrinology and Metabolism eLetter for Daly et al.

IARC 2002 Breast Cancer Screening. Lyon: IARC Press.

Jenkins PJ, Mukherjee A \& Shalet SM 2006 Does growth hormone cause cancer? Clinical Endocrinology (Oxf) 64 115-121.

Kleihues P \& Cavenee W 2000 Tumors of the Nervous System. Lyon: IARC Press.

Tworoger SS \& Hankinson SE 2006 Prolactin and breast cancer risk. Cancer Letters 38 231-239.

Tworoger SS, Sluss P \& Hankinson SE 2006 Association between plasma prolactin concentrations and risk of breast cancer among predominately premenopausal women. Cancer Research 66 2476-2482.

Vaclavicek A, Hemminki K, Bartram CR, Wagner K, Wappenschmidt B, Meindl A, Schmutzler RK, Klaes R, Untch M, Burwinkel B et al. 2006 Association of prolactin and its receptor gene regions with familial breast cancer. Journal of Clinical Endocrinology and Metabolism 91 1513-1519.

Vierimaa O, Georgitsi M, Lehtonen R, Vahteristo P, Kokko A, Raitila A, Tuppurainen K, Ebeling TM, Salmela PI, Paschke R et al. 2006 Pituitary adenoma predisposition caused by germline mutations in the AIP gene. Science $\mathbf{3 1 2}$ 1228-1230.

Webb SM, Casanueva F \& Wass JA 2002 Oncological complications of excess GH in acromegaly. Pituitary 5 21-25. 